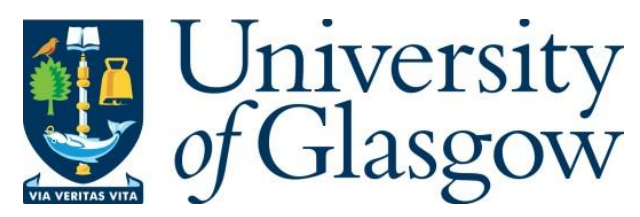

Hammill, F., Hjartarson, P. and McGregor, H. (2015) Introduction: magazines and/as media: periodical studies and the question of disciplinarity. Journal of Modern Periodical Studies, 6(2), iii-xiii.

There may be differences between this version and the published version. You are advised to consult the publisher's version if you wish to cite from it.

http://eprints.gla.ac.uk/148140/

Deposited on: 15 September 2017

Enlighten - Research publications by members of the University of Glasgow http://eprints.gla.ac.uk 


\section{Magazines and/as Media: Periodical Studies and the Question of Disciplinarity}

\section{Periodical Studies as Media Studies}

In the opening essay of this special issue, Patrick Collier asks whether a thing called "modern periodical studies" exists, and turns to the Journal of Modern Periodical Studies itself to find an answer. Appearing in the pages of the very journal that articulates the existence of such a field, this question may seem purely rhetorical. It is certainly timely: a moment of pause five years after this journal's establishment to consider what the concretion of energy and scholarly attention around periodical studies has wrought. Collier's question echoes the MLA 2013 roundtable that was in many ways the starting point for our special issue, although the editors were mere audience members. Organized by J. Stephen Murphy around the similarly evocative question "What Is a Journal?" the roundtable began from the premise that periodical studies was fragmented due to the absence of a unified theoretical framework - a move toward synthesis that, while important, is not new.

The conversations at that roundtable strongly emphasized the importance of reading magazines within networks of mediation and remediation. While Ann Ardis argued for a media ecology perspective that understands periodicals' "intermedial relationships with other communication technologies" ("Towards" 1) and Sean Latham insisted that we start thinking about modern magazines "as new media technologies" ("Affordance" 1), James Mussell called for a methodological turn shaped by attentiveness to "the way media mediate" ("Matter" 4). Specifically, Mussell emphasized the importance of sameness and repetition. This concern resonates with our sense that periodical studies is frequently structured by an implicit hierarchy of content that privileges the story over the advertisement, the enduring over the fashionable, or, more broadly, the exceptional over the repetitive. It was our desire to carry on this conversation that led to the organization of "Magazines and/as Media: Methodological Challenges in Periodical Studies," a three-day workshop held at the University of Alberta, 14-16 August 2014.

The presentations and discussions at this workshop took up the MLA panel's exhortations to think through magazines and their relation to media in two distinct but related ways. They considered, first, how magazines, whether as new media or the transitional remediation of old media, relate to the other media forms that shaped the cultural production and circulation of the late-nineteenth and earlier-twentieth centuries, including photography, radio, and film. Second, they asked how the advent of digital technologies opens new methodological avenues for engaging with periodicals" "vast and unwieldy archives" (Latham and Scholes 529). We were particularly interested in exploring methodologies and critical perspectives that resisted the privileging of canonical objects of study — such as high modernist literary production - in favour of understanding magazines as miscellany, as database, or as network, all metaphors that emphasize patterns of repetition, interlocking systems of mediation, and a certain ludic interplay of objects that resist easy differentiation and categorization.

The resulting special issues - this one, and the companion special issue of English Studies in Canada (41.1) - strive to find common approaches by exploring the ways in which various scholars' work generates productive tensions via differing conceptions of the magazine as object of study. The papers are committed to examining magazines as material objects and locating those objects in history, which also entails understanding them as a form of technology in transition. This focus on magazines and/as media demands a shift beyond the modernist little 
magazine to explore pulp and glossy and amateur periodicals, and beyond Victorian literary periodicals to examine digests, newspapers, and newsletters as vital forms of media production. Challenging the restrictive norms of discipline and brow, these special issues also strive to span a range of historical periods and geographical locales to offer a genuinely border-crossing conversation.

Periodicals are print media characterized by both seriality — single titles are instantiated across multiple issues - and periodicity - titles strive for, if they don't always achieve, a regular publication cycle that structures reader engagement. As Mussell has argued elsewhere, the "larger serial structure" of a periodical

is invoked through the repetition of certain formal features, issue after issue. It insists on a formal continuity, repeated from the past and projected onwards into the future, providing a mediating framework whose purpose is to reconcile difference and present it in a form already known to readers. The new, whether it is the next instalment of a story, a one-off essay on a new subject, or a piece of news, is always tempered, regulated within a formal framework that readers have seen before. ("In Our Last")

The continuity of a title, in short, depends upon the magazine's function as a medium. Periodicity might be described as one of the "protocols" that Lisa Gitelman attributes to media, part of that "vast clutter of normative rules and default conditions, which gather and adhere like a nebulous array around a technological nucleus" (7). While the materiality of media is central to their operation - as J. Matthew Huculak's essay on paper production and little magazines makes clear - the normative rules of their use must also be grasped. In addition to periodicity, information about subscription rates and policies, advertising, circulation networks, and reading habits is key to theorizing periodicals as media. And yet this information can be remarkably difficult to capture when approaching historical texts - especially when archival practices have ignored exactly what scholars today find most interesting. Insights into readership are particularly difficult to obtain, though periodicals scholars are finding imaginative ways of approaching the problem. For example, both Jana Smith Elford and Susan Hamilton, in this issue, as well as Andrea Hasenbank in the companion issue, are interested in the reader as a node in a network - a complex relationship among texts, producers, and readers in which periodicals participated and which periodicals might, through careful analysis, reveal. The genres of the review journal, the activist periodical, and the newsletter are ideal subjects for network analysis, as they point toward how periodicals can work to inscribe the very communities that their regular circulation also helps bring into being. Together, they also shed light on the value of reading periodicals through the critical frameworks and methods offered by media studies.

\section{The Newness of Periodical Studies?}

In her recent book on the ongoing relationship between modernism and media, Jessica Pressman makes the convincing claim that modernism - as a "strategy of innovation that employs the media of its time to reform and refashion older literary practices in ways that produce new art" is "centrally about media" (3-4). Pressman is not the first to link modernist aesthetic innovation to the rapid transformation of media technologies at the turn of the twentieth century; she identifies her indebtedness to Friedrich Kittler, Lev Manovich, and Marshall McLuhan, among others. She also echoes the work of scholars like Ardis, who argues that the turn of the twentieth century is a period of "media in transition," characterized by a complex "media ecology" that 
demands "scrupulous attention to both the materiality of print and its intermedial relationships with other communication technologies" ("Towards" 1). While Pressman leaves it out, Ardis and many other scholars make a point of including the periodical press in this media ecology, and as part of "the still broader field of 'print culture studies,' a post-disciplinary re-orientation that Victorianists have staged very productively over the last ten to fifteen years" ("Towards" 2). ${ }^{1}$

Debates over how periodicals mediate their content - and how we, as scholars, inevitably remediate them - have been a central tenet of the field since at least 1989, when Margaret Beetham pointed out that the archival practice of stripping out advertisements and binding periodical issues into volumes changes their meaning as objects of study (97). Similarly, Beetham's attention to television as a parallel medium, helpful for thinking through the dynamics of seriality, signals that media theory has long been central to the theorization of the periodical as a form. Thus, when Sean Latham and Robert Scholes announced in 2006 that the new field of "modern periodical studies" would be characterized by both an increased scholarly interest in periodicals as "autonomous objects of study" and the "still-emergent field['s] ... aggressive use of digital media" (517-18), their oft-cited article pointed both forward to a reinvigorating of the field and back to the field's long continuities.

Periodical studies - as a field that insists on the value of reading across full issues and multi-year runs of serial texts rather than cherry-picking individual items - has indeed benefitted from the increase in large-scale digitization projects that make rare periodical titles widely available. The twenty-year-old Modernist Journals Project (MJP) is responsible for a variety of important initiatives, such as the digitization of full magazine runs that include advertising as well as covers - paratextual material often stripped away during the process of archivization and thus difficult to locate, but central to our understanding of magazines as a medium. The MJP has been joined by a variety of other digitization initiatives. Even the briefest survey of these projects demonstrates their historical and aesthetic range. The UK-based Modernist Magazines Project arrived in 2006, followed in 2011 by The Pulp Magazines Project. Starting in 2009, the Chinese Women's Magazines project has been developing a database of popular women's magazines published between 1904 and 1937. In 2012 The Yellow Nineties launched, offering open-access digital facsimiles of the "avant-garde aesthetic periodicals that flourished in Great Britain at the fin-de-siècle." Between 2011 and 2013 Magazines, Travel and Middlebrow Culture in Canada 1925-1960 created a searchable catalogue derived from the tables of contents of selected Canadian middlebrow magazines, ${ }^{2}$ in 2014 Modern Magazines Project Canada continued the work on Canadian household magazines by collaborating with the University of Alberta Libraries Digital Initiatives to digitize the complete thirty-two year run of The Western Home Monthly, the largest single magazine digitization project to date. ${ }^{3}$

\footnotetext{
${ }^{1}$ Scholars of Romanticism have also contributed towards developing a media studies approach to book history and print culture studies. In July 2015, for instance, a symposium at the University of Edinburgh titled "Books and/as New Media" took up remediation and intermediality in the context of the history of the book in the eighteenth and nineteenth centuries.

2 The book on Canadian middlebrow periodicals emerging from this project models the kinds of periodical scholarship that emerges at the intersection of media studies and literary studies (see Hammill and Smith).

${ }^{3}$ For a discussion of the process of digitizing a periodical archive, and its impact on scholarly understandings of the periodical as a medium, see McGregor.
} 
Digitization has also opened up new methodological possibilities for reading across massive multi-year archives, methodologies that take advantage of machine-reading to compensate for the limits of human memory and time. In his contribution to JMPS's special issue on "Visualizing Periodical Networks," Jeff Drouin articulates the benefits of combining close and distant reading, or "micro and macro analysis" (111):

The point is not that digital methods in distant reading should replace traditional techniques, but rather that they should show us where to apply them or suggest answers where the print trail is inconclusive. ... The computer shows us interesting patterns that can shape our inquiry, prompt us to ask new questions, and test assumptions. (130)

Drouin's article clearly explicates how digital methods have enabled a richer understanding of magazines as media, rather than texts or repositories of historical information (see also Latham, "Unpacking"). The process of reading a magazine involves actively assembling the different components - articles, advertisements, illustrations, letters to the editor, etc. - into an unpredictable, idiosyncratic, and ultimately unstable whole. With its capacity for reading across large quantities of text in non-linear ways and discovering unlikely patterns, distant reading is a promising method for capturing this quality of emergence, and thus for better understanding the unique properties of magazines as media.

These digitization projects, alongside the methodologies and findings they have led to, are excitingly new, offering not only access to previously marginalized materials but also new ways of reading familiar texts. That exciting newness, however, poses its own dangers. First, we risk forgetting that the history of periodical studies has been a history of studying mediations and their remediations. From Beetham's questioning of what is lost when periodicals are bound into volumes to recent scholars" worries about the "offline penumbra" (Leary 82) of magazines that are not digitized, new technologies of preservation bring both losses and new possibilities for research. Perhaps the greatest risk, as Maria DiCenzo argues in the opening essay in our companion special issue, is the "rhetoric of newness" itself, with its "self-reinforcing narratives about emergence and innovation," and the disciplinary blindness that results: "the effect of ahistorical approaches to the criticism (of looking only forward and not back) is to miss or dismiss decades of valuable scholarship. In order not to keep starting from scratch, it is important to highlight the longer history and discourage the idea that period- and discipline-specific or nationally-based studies might preclude our interest" (23-24). As we argued above, the field of periodical studies is characterized by marked continuities - continuities that have been ill-served by the disciplinary boundaries that have siloed and divided periodical scholars.

\section{The Question of Disciplinarity}

The two linked special issues strive to highlight these continuities, celebrating what is innovative in recent turns in periodical studies while paying heed to the field's long history. In 1989, Laurel Brake and Anne Humphreys pointed out the need to start theorizing periodicals, to stop "'using,' more or less uncritically, selected parts of the Victorian periodical press as reflections of readership, attitudes, and responses" (94). That this same point had to be made at the announcement of "modern periodical studies" in 2006 says much about how periodical studies has suffered from a lack of communication across areas of specialism. It is for this reason that we, the editors, strive to contribute to a body of work that bridges the "great divides" Ardis has identified in this field: 
the divide between all things "Victorian" or "traditional" and all things "modern" or "modernist" (with the former often construed reductively to privilege the newness of twentieth-century artistic and cultural phenomena); the divides between both "literature" and what Laurel Brake has termed the "subjugated knowledges" of journalism and between high and low culture; and the divide between art (or modernist high seriousness, more particularly) and everyday life. ("Editor's Introduction" v-vi)

The periodicals discussed across the twelve articles in these special issues range from the 1870s to the 1940s, from Britain to Canada to the US to Australia, from pulp to middlebrow to avantgarde. The methodological approaches are accordingly, and appropriately, diverse. In fact the sheer variety of approaches invites another key question: whether periodical studies needs consolidation as a field, or if its strength in fact lies in its heterogeneity and interdisciplinarity. These joint special issues can be read as an experiment in finding sites of exchange across disciplinary, geographical, and chronological boundaries, united by our interest in reading periodicals through, as, and alongside media.

The articles in the ESC issue, titled "Magazines and/as Media: The Politics and Aesthetics of Periodical Form," were chosen for the way their individual case studies illuminate what is at stake both theoretically and politically in our understanding not just of what a periodical is, but of how it operates. In this issue of JMPS, Collier notes that the field of modern periodical studies is riven by implicit, though rarely stated, dissent over "what the object of knowledge is in modern periodical studies" (TK). The essays below take up his provocation by testing a variety of answers: is the periodical a serial system that produces social action through codified genres, or a circulating media object capable of carrying materials across spaces both social and geographical? Is it a material instantiation of the multiple nodes in a social network, or a paper product that taps into transatlantic circuits of colonial exploitation and commodity exchange? Collectively, these articles articulate the fundamental interdisciplinarity of periodical studies, revealing how the very contention over our object of study is what allows the periodical to cut across disciplinary borders.

In the opening essay, "What is Modern Periodical Studies?," Patrick Collier reads five years' worth of issues of the JMPS. He points out that recent research has greatly expanded the scope of periodical studies by taking in a greater variety of types of publication. Nevertheless, "the imprimatur of modernist literary study is strong on the JMPS," and this tends to limit the ability of modern periodical studies to "expand the literary field" (TK). On methodological questions, Collier enters into dialogue with Maria DiCenzo's essay in the companion special issue, reflecting on her suggestion that new methods of machine reading are producing a rift in scholarly practice, dividing the distant from the close readers. Collier concludes that both kinds of reading are needed, as well as the "surface reading" advocated by Margaret Cohen. $\mathrm{He}$ speculates that "as modern periodical studies matures, it will create a feedback loop in which computer-assisted data mining and visualization will be used to extend and validate hypotheses generated through close-reading ... while larger patterns unearthed by distant reading make available new texts and concepts to be explored in close reading" (TK).

While Collier invites us to venture away from cultural studies and modernist studies and back toward the periodical as object, Will Straw, in "Constructing the Canadian Low-Brow Magazine: The Periodical as Media Object in the 1930s and 1940s," shows how attention to the print object leads us into media studies. Straw focuses on "spicy" English-Canadian magazines 
JMPS Introduction

such as Broadway Brevities and Canadian Tattler, exploring "the varieties of physical deformation" that came to typify them (TK). These included the insertion of materials previously published in the United States and often gained illicitly, as well as the erasure of information about the date and place of publication and a degradation of paper and reproduction quality. By considering these magazines as media objects, Straw demonstrates how they undermine some of the methodological truisms of periodical studies, including the impulses to "study periodicals in terms of the manner in which their temporalities of circulation serve to constitute publics" and to "study ... readership as key to the understanding of a magazine's social life" (TK). He concludes that, "in the study of minor cultural forms (like avant-garde poetry or versions of Canadian popular culture), the struggle to produce will almost always involve processes of greater complexity than will the rare and typically isolated actions through which these forms are consumed" (TK).

Susan Hamilton, in "“[T]o bind together in mutual helpfulness': Genre and/as Social Action in the Late Victorian Anti-Vivisection Press," examines the serial genres adopted by two anti-vivisection journals, The Zoophilist and The Home Chronicle. Her essay "contributes to the enduring question of what a periodical is, by returning to the question of what periodicals $d o$ " (TK) - that is, how they circulated and how they attempted to intervene in the world by prompting readers to action. Focusing on questions of temporality, she argues that these advocacy serials were "one part of an orchestrated cycle of publication conceived to keep antivivisection in the news, and so in the minds of readers" (TK). The essay demonstrates that while the study of these periodicals can shed much light on the history of Victorian social movements, the analysis can also be approached from the opposite direction. That is, knowledge of how Victorian campaigns were organised can illuminate the generic and material forms that the serials took, and the way these changed over time.

From Hamilton's interest in what periodicals do, J. Matthew Huculak turns to the question of what periodicals are made of. In his essay "Modernist Papers and Canadian Pulp: Transatlantic Networks of Magazine Materiality," Huculak proposes that scholars of modernist print culture, and of periodicals in particular, need to be more attentive to paper. The essay argues that the same attention to forensic, or evidence-based, materiality that is now infiltrating digital media studies should be equally brought to bear on the new media of the twentieth century, particularly the modernist little magazine. This attention to paper in turn leads to a consideration of the economics of empire and colonial expansion, and to the silenced histories of labour that underpin modernist production. Huculak advocates the creation of a descriptive framework for what he calls the "forensics of magazine materiality," a framework that can account for "the material trade networks of production" (TK).

The final essay, Jana Smith Elford's "Recovering Women's History with Network Analysis: A Case Study of the Fabian News," offers a critique of standard historical narratives of late Victorian feminism and the role of the Fabian Society by demonstrating the hermeneutic possibilities of network analysis. Through a carefully accumulated database of people, events, publications, and topics mined from the pages of the Fabian News, Smith Elford shows how networks can upend common sense understandings of history and offer alternative feminist historiographies of political movements. Using digital network visualization software "not just as a tool but instead as a methodological approach," she aims to arrive at "a better understanding of how the newsletter itself might function as an alternate archive" (TK). In the process, she demonstrates that a turn to new tools and methods need not constitute a turn away from historicism. 
Uniting these diverse essays is a commitment to reading magazines not as transparent containers of information but rather as complex media artefacts whose relation to their cultural and political contexts is articulated through rhythms of seriality, patterns of remediation, and material systems of production and circulation. Like the ESC companion issue, this special issue is committed to locating periodical studies at the interstices of a variety of fields, methodologies, and historical periods. Our goal is not to synthesize but to juxtapose. These articles, while focusing on a heterogeneous set of case studies, reveal the emergence of a shared critical discourse and a shared set of methods for reading periodicals as, and in relation to, media.

\section{Acknowledgements}

The editors would like to thank the many collaborators and sponsors who made these joint special issues, and the workshop that inspired them, possible: our inimitable research assistant, Clare Mulcahy; at ESC, Michael O'Driscoll, Mark Simpson, and Sylvia Vance; at JMPS, Sean Latham and Mark Morrison; the Social Sciences and Humanities Research Council of Canada; the University of Alberta Libraries Digital Initiatives; the University of Strathclyde; the Royal Society of Edinburgh; the Kule Institute for Advanced Study; James Cook University; Eighteen Bridges magazine; the Alberta Magazine Publishers Association; the Canadian Literature Centre; and the University of Alberta Faculty of Arts.

\section{Works Cited}

Ardis, Ann. "Editor's Introduction. Mediamorphosis: Print Culture and Transatlantic/Transnational Public Sphere(s)." Modernism/modernity 19.3 (2012): v-vii. Web. 14 May 2015.

---. "Towards a Theory of Periodical Studies." What is a Journal? Towards a Theory of Periodical Studies. MLA Convention 2013, Special Session 384. Web. 21 Dec. 2012.

Beetham, Margaret. "Open and Closed: The Periodical as a Publishing Genre." Victorian Periodicals Review 22.3 (1989): 96-100. Web. 30 June 2015.

Brake, Laurel, and Anne Humphreys. "Critical Theory and Periodical Research." Victorian Periodicals Review 22.3 (1989): 94-95. Web. 4 June 2015.

DiCenzo, Maria. "Remediating the Past: Doing 'Periodical Studies' in the Digital Era." Magazines and/as Media: The Aesthetics and Politics of Serial Form. Ed. Faye Hammill, Paul Hjartarson, and Hannah McGregor. Spec. issue of English Studies in Canada 41.1 (2015): 19-39.

Drouin, Jeffrey. "Close- and Distant-Reading Modernism: Network Analysis, Text Mining, and Teaching The Little Review." Visualizing Periodical Networks. Ed. J. Stephen Murphy. Spec. issue of Journal of Modern Periodical Studies 5.1 (2014): 110-35. Web. 14 May 2015.

Gitelman, Lisa. Always Already New: Media, History, and the Data of Culture. Cambridge: MIT Press, 2008. Print.

Hammill, Faye, and Michelle Smith. Magazines, Travel, and Middlebrow Culture: Canadian Periodicals in English and French, 1925-1960. Liverpool: Liverpool UP, 2015. Print.

Hasenbank, Andrea. "Assembling Lines: Researching Radical Print Networks." Magazines and/as Media: The Aesthetics and Politics of Serial Form. Ed. Faye Hammill, Paul Hjartarson, and Hannah McGregor. Spec. issue of English Studies in Canada 41.1 (2015): $129-53$. 
Latham, Sean. "Affordance and Emergence: Magazine as New Media." What is a Journal? Towards a Theory of Periodical Studies. MLA Convention 2013, Special Session 384. Web. 21 Dec. 2012.

---. "Unpacking My Digital Library: Programming Modernist Magazines.” Editing Modernisms in Canada. Ed. Colin Hill and Dean Irvine. Toronto: U of Toronto P, 2015. Forthcoming. Latham, Sean, and Robert Scholes. "The Rise of Periodical Studies." PMLA 121.2 (2006): 517531. Web. 28 June 2011.

Leary, Patrick. "Googling the Victorians." Journal of Victorian Culture 10 (2005): 72-86. Print. McGregor, Hannah. "Remediation as reading: digitising The Western Home Monthly." Archives and Manuscripts 42.3 (2014): 248-257. Web. 18 Nov. 2014.

Mussell, James. "'In Our Last': the Presence of the Previous in Periodical Form." Ms. Courtesy of the author. Victorian Periodicals Review (2015). Forthcoming.

---. "The Matter with Media." What is a Journal? Towards a Theory of Periodical Studies. MLA Convention 2013, Special Session 384. Web. 21 Dec. 2012.

Pressman, Jessica. Digital Modernism: Making it New in New Media. Oxford Scholarship Online, 2014. Web. 21 Nov. 2014. 